\title{
Aortic Injury, CTCAE
}

National Cancer Institute

\section{Source}

National Cancer Institute. Aortic Injury, CT CAE. NCI Thesaurus. Code C143289.

A finding of damage to the aorta. 